\title{
Adaptive responses in men fed low- and high-copper diets
}

\author{
Linda J. Harvey ${ }^{1 \star}$, Gosia Majsak-Newman ${ }^{1}$, Jack R. Dainty ${ }^{1}$, D. John Lewis ${ }^{2}$, \\ Nicola J. Langford ${ }^{2}$, Helen M. Crews ${ }^{2}$ and Susan J. Fairweather-Tait ${ }^{1}$ \\ ${ }^{1}$ Nutrition and Consumer Science Division, Institute of Food Research, Norwich Research Park, Colney, \\ Norwich NR4 7UA, UK \\ ${ }^{2}$ Central Science Laboratory, Sand Hutton, York YO41 1LZ, UK
}

(Received 11 March 2002 - Revised 11 February 2003 - Accepted 3 March 2003)

\begin{abstract}
The study of $\mathrm{Cu}$ metabolism is hampered by a lack of sensitive and specific biomarkers of status and suitable isotopic labels, but limited information suggests that $\mathrm{Cu}$ homeostasis is maintained through changes in absorption and endogenous loss. The aim of the present study was to employ stable-isotope techniques to measure $\mathrm{Cu}$ absorption and endogenous losses in adult men adapted to low, moderate and high $\mathrm{Cu}$-supplemented diets. Twelve healthy men, aged 20-59 years, were given diets containing $0 \cdot 7,1.6$ and $6 \cdot 0 \mathrm{mg} \mathrm{Cu} / \mathrm{d}$ for 8 weeks, with at least 4 weeks intervening washout periods. After 6 weeks adaptation, apparent and true absorption of $\mathrm{Cu}$ were determined by measuring luminal loss and endogenous excretion of $\mathrm{Cu}$ following oral administration of $3 \mathrm{mg}$ highly enriched ${ }^{65} \mathrm{Cu}$ stable-isotope label. Apparent and true absorption ( 41 and $48 \%$ respectively) on the low-Cu diet were not significantly different from the high-Cu diet (45 and $48 \%$ respectively). Endogenous losses were significantly reduced on the low- $(0.45 \mathrm{mg} / \mathrm{d} ; P<0.001)$ and medium- $(0.81 \mathrm{mg} / \mathrm{d} ; P=0.001) \mathrm{com}-$ pared with the high-Cu diet $(2.46 \mathrm{mg} / \mathrm{d})$. No biochemical changes resulting from the dietary intervention were observed. Cu homeostasis was maintained over a wide range of intake and more rapidly at the lower intake, mainly through changes in endogenous excretion.
\end{abstract}

Copper: Fructose: Stable isotopes: Copper absorption: Copper endogenous losses

Whole-body $\mathrm{Cu}$ balance (homeostasis) is maintained by a combination of changes in absorptive efficiency of the intestinal mucosal cells and quantity of endogenous $\mathrm{Cu}$ excreted via the gastrointestinal tract. At low and high intakes the efficiency of absorption is up and down regulated respectively, but adaptation is more rapid with a low $\mathrm{Cu}$ intake (Turnlund et al. 1989). The extent to which this endogenously excreted $\mathrm{Cu}$ is reabsorbed from the gut is not known (Linder, 1991).

$\mathrm{Cu}$ absorption decreases with malnutrition and in various disease states with malabsorption syndromes, for example, coeliac disease (Cordano et al. 1964; Goyens et al. 1985), and several dietary factors reduce absorption, for example, antacids, infant cows' milk formulas (Dorner et al. 1989), Zn (Turnlund et al. 1988; August et al. 1989) and fructose. The $\mathrm{Cu}$-fructose interaction is potentially the most important due to the increasing consumption of fructose in the Western diet. However, the mechanisms are uncertain because the results of human studies have proved difficult to interpret. Fructose has been found to impair $\mathrm{Cu}$ status, whilst $\mathrm{Cu}$ balance appears to be increased (Reiser et al. 1985).

$\mathrm{Cu}$ absorption has been measured in human volunteers using a highly enriched ${ }^{65} \mathrm{Cu}$ stable isotope, with doses corresponding to 50-200\% of typical daily intakes (August et al. 1989; Turnlund et al. 1991). In these studies, the unabsorbed $\mathrm{Cu}$ isotope is excreted in the faeces within $5-7 \mathrm{~d}$, followed by smaller amounts of isotope that have been absorbed and then re-excreted (endogenous loss). Thus the period of time over which the faecal collections are made is critical; if it is too short then the apparent absorption (intake minus luminal loss) will be overestimated, as not all of the unabsorbed $\mathrm{Cu}$ will have been excreted. In addition, it is only possible to calculate true absorption if endogenous excretion has been estimated from the appearance of absorbed isotope in the later faecal collections.

The aim of the present study was to determine $\mathrm{Cu}$ absorption, retention and endogenous losses following equilibration at different levels of intake of $\mathrm{Cu}$, from that found in diets low in $\mathrm{Cu}$ to a level generally only attainable with $\mathrm{Cu}$ supplements. In the absence of a sensitive and specific index of $\mathrm{Cu}$ status, this was believed to be the best approach for generating information needed to assess the public health significance of low and high $\mathrm{Cu}$ intakes. A range of biochemical assays was undertaken at the beginning and end of each dietary intervention in order to underpin the metabolic measurements.

\footnotetext{
Abbreviations: GPx, glutathione peroxidase; ICP-MS, inductively coupled plasma-mass spectrometry; IFR, Institute of Food Research; SOD, $\mathrm{Cu}, \mathrm{Zn}$-superoxide dismutase.

* Corresponding author: Dr Linda Harvey, fax +44 1603 507723, email linda.harvey@bbsrc.ac.uk
} 


\begin{abstract}
Methods
Subjects

Twelve healthy men were recruited to a residential, longitudinal intervention study (subject characteristics are given in Table 1). A screening blood sample $(10 \mathrm{ml})$ was taken to exclude volunteers whose biochemical and haematological indices lay outside the normal range. Other exclusion criteria included chronic illness, taking medication or nutritional supplements, and smoking. The aims and procedures of the study were explained to the volunteers during a visit to the Human Nutrition Unit at the Institute of Food Research (IFR) and written informed consent was obtained. The IFR Human Research Ethics Committee approved the protocol and the study was conducted in accord with the Helsinki Declaration of 1975 as revised in 1983.
\end{abstract}

\section{Study design}

The subjects were resident in the Human Nutrition Unit for three periods of 8 weeks with a minimum washout of 4 weeks between study periods. A diet low in $\mathrm{Cu}$ was fed throughout the study using a $7 \mathrm{~d}$ rotating menu consisting of three meals per $\mathrm{d}$ and snacks. Additional $\mathrm{Cu}$ was added to the diets in the form of copper sulfate with each meal, such that the total daily intake was 1.6 and $6.0 \mathrm{mg}$ during the first and third dietary periods respectively. The diets were regularly analysed to ensure that the $\mathrm{Cu}$ content remained constant from batch to batch. During each study period, the energy intakes of the subjects were adjusted as necessary in order to maintain body weight by the addition of either a commercially available dextrose drink or yoghurt. The mean $\mathrm{Cu}$ content of the diet analysed by atomic absorption spectroscopy was 0.69 (SD 0.02) mg/d. All other dietary variables were within customary UK limits. The diet had a mean daily energy intake of $10.78 \mathrm{MJ}(2577 \mathrm{kcal})$, of which $12 \%$ was from protein, $52 \%$ from carbohydrate and $36 \%$ from fat. The mean calculated daily mineral content of the diet was $2845 \mathrm{mg} \mathrm{K}$, $2234 \mathrm{mg} \mathrm{Na}, 1299 \mathrm{mg} \mathrm{Ca}, 2918 \mathrm{mg} \mathrm{Mg}, 7.7 \mathrm{mg} \mathrm{Fe}$ and $7.6 \mathrm{mg} \mathrm{Zn}$. The habitual dietary $\mathrm{Cu}$ intake of each volunteer was assessed before the residential part of the study. Each volunteer kept a $7 \mathrm{~d}$ weighed food intake diary, which was analysed for $\mathrm{Cu}$ content using food composition tables (Royal Society of Chemistry, 1991). Subjects also collected $24 \mathrm{~h}$ duplicate diets during this period. The daily collections were homogenised and analysed for $\mathrm{Cu}$ content using the inductively coupled plasma-mass spectrometry (ICPMS) facility at the Central Science Laboratory.

On day 42 of each dietary period, following a $12 \mathrm{~h}$ overnight fast, each volunteer received a $3 \mathrm{mg}$ oral dose of

Table 1. Subject characteristics

(Mean values and standard deviations for twelve subjects)

\begin{tabular}{lccc}
\hline & Mean & SD & Range \\
\hline Age (years) & 32 & 11 & $20-59$ \\
Height $(\mathrm{m})$ & 1.79 & 0.06 & $1.70-1.94$ \\
Weight $(\mathrm{kg})$ & 78.4 & 9.3 & $67.8-100.3$ \\
BMl $\left(\mathrm{kg} / \mathrm{m}^{2}\right)$ & 24 & 2 & $20-28$ \\
\hline
\end{tabular}

the highly enriched ${ }^{65} \mathrm{Cu}$ stable isotope in $130 \mathrm{~g}$ of a diet cola drink together with a low-Cu meal consisting of $70 \mathrm{~g}$ white bread and $17 \mathrm{~g}$ butter. The cola drink also contained $1 \mathrm{mg}$ of the rare earth element Ho, which acted as a non-absorbable faecal marker (Harvey et al. 2002). Six of the volunteers (randomly assigned) also received $25 \mathrm{~g}$ fructose dissolved in the cola drink. The effect of the fructose was not evaluated. The volunteers refrained from eating and drinking (except demineralised water) for $4 \mathrm{~h}$ following the test meal. Complete faecal collections were made for a period of approximately $14 \mathrm{~d}$ post-dosing and each subject also collected a baseline faecal sample before the test meal.

Fasting blood samples were taken on days 1 and 42 of each dietary period for a range of biochemical assays (see p. 163).

\section{Dose preparation}

Isotopically enriched copper chloride $\left({ }^{65} \mathrm{CuCl}_{2}\right)$ was prepared from elemental ${ }^{65} \mathrm{Cu}$ (Europa Scientific Ltd, Crewe, UK) by dissolving the metal in $10 \mathrm{ml}$ concentrated $\mathrm{HNO}_{3}(\mathrm{BDH}$, Poole, UK) (Aristar grade) and evaporating to virtual dryness. The sample was then taken up in $0.1 \mathrm{M}-\mathrm{HCl}(25 \mathrm{ml}$; BDH, Aristar grade) and again evaporated to almost dryness; this stage was then repeated twice more and finally the sample was taken up in an appropriate volume of $0.1 \mathrm{M}-\mathrm{HCl}$ to give an approximate concentration of $1 \mathrm{mg} / \mathrm{ml}$. The concentration was accurately determined by ICP-MS. The solution was divided into individual doses and stored in plastic vials at $-20^{\circ} \mathrm{C}$ until required.

The Ho oral doses were prepared by dissolving holmium chloride (Avocado Research Chemicals Ltd, Heysham, UK) in demineralised, purified water (Elga, Cambridge) to concentrations of approximately $0.5 \mathrm{mg} / \mathrm{ml}$. The solution was divided into individual $1 \mathrm{mg}$ doses and stored in plastic vials at $-20^{\circ} \mathrm{C}$ until required and the concentration accurately determined by ICP-MS.

\section{Sample preparation and analysis}

Faecal samples were autoclaved, freeze-dried, ground to a fine powder using a mortar and pestle, and sub-sampled. Before analysis by ICP-MS, portions of faecal samples $(0.5 \mathrm{~g})$ were digested in concentrated nitric acid $(5 \mathrm{ml})$ using a high temperature-pressure microwave digestion system and the digest fluid diluted 50-fold with distilled water containing $\mathrm{Ga}(50 \mathrm{ng} / \mathrm{ml})$ as an internal standard. The total levels of $\mathrm{Cu}$ and the ${ }^{63} \mathrm{Cu}:{ }^{65} \mathrm{Cu}$ isotope value in the solutions were measured using a VG Plasmaquad Turbo II Plus ICP-MS (VG Elemental, Winsford, UK) (Baxter et al. 1997). The quality of the analytical data was assessed in two ways; first, by the use of a certified reference material (BCR 422 cod muscle), and second, by the recovery of a known amount of added analyte. Ho concentrations were also quantified by ICP-MS (Baxter et al. 1997).

\section{Biochemical assays}

Blood samples collected on days 1 and 42 were prepared for various analyses performed either at the IFR or at the Chemical Pathology Department of the Norfolk and 
Norwich Hospital (Norwich, UK). Analyses performed by the Chemical Pathology Department included serum $\mathrm{Cu}$, caeruloplasmin, C-reactive protein and a full lipid screen. Serum $\mathrm{Cu}$ was measured by atomic absorption spectroscopy (Phillips model no. PU9200; Phillips, Cambridge, UK) and total caeruloplasmin by an immunoturbidimetry assay (Dako, High Wycombe, UK). The inter-assay CV were 6.4 and $10 \%$ for the $\mathrm{Cu}$ and caeruloplasmin respectively. Serum samples were also analysed for triacylglycerols and total, LDL- and HDL-cholesterol; LDL-cholesterol was calculated using the Friedewald equation (Friedewald et al. 1972). Apolipoprotein A1 and B concentrations were determined using immunoturbidimetry assays (IMMUNO, Ltd., Sevenoaks, Kent, UK) automated on a Cobas Fara centrifugal analyser (Roche, Welwyn Garden City, UK). In order to eliminate raised caeruloplasmin or ferritin concentrations that resulted from an inflammatory response or infection, C-reactive protein concentrations were determined using an immunoturbidimetry assay (Dako). Caeruloplasmin activity was determined at the Northern Ireland Centre for Diet and Health using a modified method of Henry et al. (1960) on an autoanalyser (Cobas Fara; Roche).

The remaining assays were performed at the IFR using an autoanalyser (Cobas Mira; Roche). Control serum (Serum N; Roche) and quality control samples prepared in-house were used for each assay as appropriate:

(a) $\mathrm{Cu}, \mathrm{Zn}$-superoxide dismutase (SOD) was measured in erythrocytes using a commercial kit (Ransod kit; Randox Laboratories, Crumlin, UK) based on a modified method of Jones \& Suttle (1981). SOD activity was expressed in terms of SOD units/g haemoglobin measured by Drabkin's method (Drabkins \& Austin, 1932) standardised with cyanomethaemoglobin (BDH standard).

(b) Glutathione peroxidase (GPx) activity was determined in plasma, platelets and erythrocytes using a commercially available kit (Ransel test kit; Randox Laboratories) based on a modified method of Paglia \& Valentine (1967). Gpx activity was expressed in terms of protein concentration (Unimate 7 Total protein kit; Roche) in plasma and platelets (GPX activity/g protein) and haemoglobin concentration in erythrocytes (Gpx activity/g haemoglobin).

(c) Plasma ferritin was determined by an in-house ELISA assay using A133-rabbit anti-human ferritin coating anti-body and P145-rabbit anti-human ferritin detector antibody, peroxidase conjugated (Dako). The assay was standardised using the 3rd International Standard for Ferritin (National Institute for Biological Standards and Control, Potters Bar, UK).

(d) Platelet aggregation was determined as a response to $\mathrm{ADP}$ at a final concentration of $2 \times 10^{-5} \mathrm{~mol} / \mathrm{l}$ in citrated blood using a platelet aggregation profiler (model PAP-4; Bio/Data Corporation, Horsham, PA) (Williams et al. 1977).

(e) Other haematological indices including haemoglobin, packed cell volume and mean cell haemoglobin concentration were measured using an MD8 Coulter Counter (Coulter Electronics Ltd, Hialeah, FL, USA).

\section{Mathematical analysis}

Quantities of labelled and unlabelled $\mathrm{Cu}$ were calculated according to the method described in Harvey et al. (2002); this paper also details the calculation of endogenous losses from the labelled $\mathrm{Cu}$ dose. Fig. 1 shows an overview of the labelled and unlabelled $\mathrm{Cu}$ absorption and excretion that was measured and calculated in the present study. The following equations were used to generate the results shown in Tables 2 and 6 .

\section{Labelled copper absorption and excretion.}

$$
\begin{aligned}
\text { Apparent absorption } & =\left(\mathrm{D}_{\mathrm{L}}-\mathrm{R}_{\mathrm{L}}\right) / \mathrm{D}_{\mathrm{L}}, \\
\text { True absorption } & =\left(\mathrm{D}_{\mathrm{L}}-\mathrm{R}_{\mathrm{L}}+\mathrm{E}_{\mathrm{L}}\right) / \mathrm{D}_{\mathrm{L}} \\
& =\mathrm{A}_{\mathrm{L}} / \mathrm{D}_{\mathrm{L}}=\mathrm{A}_{\mathrm{U}} / \mathrm{D}_{\mathrm{U}},
\end{aligned}
$$

where $\mathrm{D}_{\mathrm{L}}$ is the labelled $\mathrm{Cu}$ dose, $\mathrm{R}_{\mathrm{L}}$ is the labelled $\mathrm{Cu}$ recovered in faeces, $A_{L}$ is the absorbed labelled $\mathrm{Cu}, \mathrm{A}_{\mathrm{U}}$ is the absorbed unlabelled $\mathrm{Cu}$ and $\mathrm{D}_{\mathrm{U}}$ is the unlabelled $\mathrm{Cu}$ in the diet. Endogenous loss $\left(\mathrm{E}_{\mathrm{L}} ; \mathrm{mg}\right)=\mathrm{F}_{\mathrm{L}}+\mathrm{S}_{\mathrm{L}}$ where $\mathrm{F}_{\mathrm{L}}(\mathrm{mg})$ is the loss of labelled $\mathrm{Cu}$ from a 'fast' pool and $S_{L}(m g)$ is the loss of labelled $\mathrm{Cu}$ from a 'slow' pool. Labelled $\mathrm{Cu}$ from the fast pool is defined to be $\mathrm{Cu}$ that was absorbed from the dose and then excreted within $14 \mathrm{~d}$. Labelled $\mathrm{Cu}$ from the slow pool is defined to be $\mathrm{Cu}$ that was absorbed from the dose and excreted more than $14 \mathrm{~d}$ after the dose. Since the study period is only $14 \mathrm{~d}$, labelled $\mathrm{Cu}$ from the slow pool is not measured and $\mathrm{S}_{\mathrm{L}}=0$. Therefore all the endogenous losses of labelled $\mathrm{Cu}$ are from the fast pool, i.e. $\mathrm{E}_{\mathrm{L}}=\mathrm{F}_{\mathrm{L}}$.

$$
\begin{aligned}
& \text { Endogenous loss (as a fraction of dose) } \\
& \quad=\mathrm{E}_{\mathrm{L}} / \mathrm{D}_{\mathrm{L}}=\mathrm{F}_{\mathrm{L}} / \mathrm{D}_{\mathrm{L}}=\mathrm{F}_{\mathrm{U}} / \mathrm{D}_{\mathrm{U}},
\end{aligned}
$$

where $\mathrm{F}_{\mathrm{U}}$ is the rate of loss of unlabelled $\mathrm{Cu}$ from the 'fast' pool in $\mathrm{mg} / \mathrm{d}$.

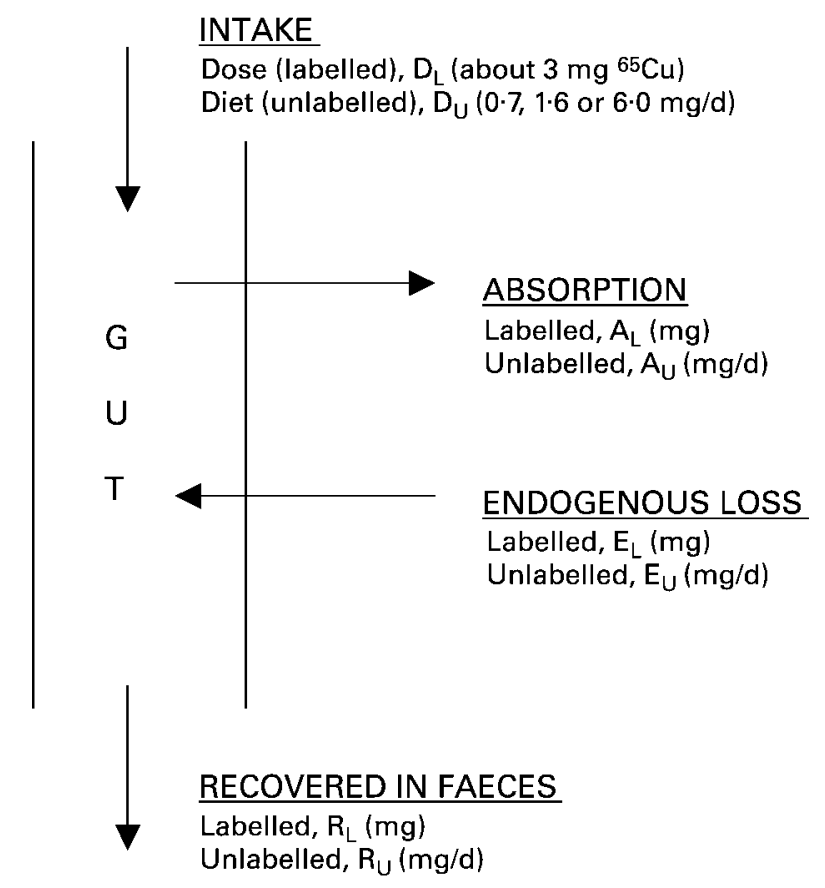

Fig. 1. Overview of labelled and unlabelled copper absorption and excretion. 
Unlabelled copper balance and excretion. In an analogous way to the labelled $\mathrm{Cu}$, unlabelled $\mathrm{Cu}$ from the fast pool is defined as $\mathrm{Cu}$ that was absorbed from a meal and then excreted within $14 \mathrm{~d}$. Unlabelled $\mathrm{Cu}$ from the slow pool is defined to be $\mathrm{Cu}$ that was absorbed from a meal and excreted more than $14 \mathrm{~d}$ after the meal.

$$
\text { Balance }(\mathrm{mg} / \mathrm{d})=\mathrm{D}_{\mathrm{U}}-\mathrm{R}_{\mathrm{U}} \text {, }
$$

where $R_{U}$ is the unlabelled $\mathrm{Cu}$ recovered in faeces.

Endogenous loss $\left(\mathrm{E}_{\mathrm{U}} ; \mathrm{mg} / \mathrm{d}\right)=\mathrm{R}_{\mathrm{U}}-\mathrm{D}_{\mathrm{U}}+\mathrm{A}_{\mathrm{U}}=$ $R_{U}-D_{U}+\left(D_{U} \times A_{L}\right) / D_{L}$ (from equation (1)).

Unlabelled $\mathrm{Cu}$ from the 'fast' pool $\left(\mathrm{F}_{\mathrm{U}} ; \mathrm{mg} / \mathrm{d}\right)=\mathrm{E}_{\mathrm{L}} \times \mathrm{D}_{\mathrm{U}} /$ $\mathrm{D}_{\mathrm{L}}$ (from equation (2)).

Since $\mathrm{E}_{\mathrm{L}}, \mathrm{D}_{\mathrm{U}}$ and $\mathrm{D}_{\mathrm{L}}$ are all known or measured, $\mathrm{F}_{\mathrm{U}}$ can be calculated. These results are shown in Table 2 in the 'fast pool' section.

Unlabelled $\mathrm{Cu}$ from the 'slow' pool $\left(\mathrm{S}_{\mathrm{U}} ; \mathrm{mg} / \mathrm{d}\right)=$ $\mathrm{E}_{\mathrm{U}}-\mathrm{F}_{\mathrm{U}}$.

Therefore, on substitution and rearrangement,

$$
\mathrm{S}_{\mathrm{U}}=\left(\left(\mathrm{R}_{\mathrm{U}} \times \mathrm{D}_{\mathrm{L}}\right)-\left(\mathrm{R}_{\mathrm{L}} \times \mathrm{D}_{\mathrm{U}}\right)\right) / \mathrm{D}_{\mathrm{L}} .
$$

Since $\mathrm{R}_{\mathrm{U}}, \mathrm{R}_{\mathrm{L}}, \mathrm{D}_{\mathrm{U}}$ and $\mathrm{D}_{\mathrm{L}}$ are all known or measured, $\mathrm{S}_{\mathrm{U}}$ can be calculated. These results are shown in Table 2 in the 'slow pool' section.

\section{Statistical analysis}

All data are expressed as means and standard deviations. ANOVA with repeated measures was used to determine the effect of dietary $\mathrm{Cu}$ intake on the efficiency of $\mathrm{Cu}$ absorption and excretion. If a significant difference was found, the least squares difference test was used to determine which treatment means differed. Student's $t$ test was used to determine the difference between measured and calculated habitual dietary $\mathrm{Cu}$ intakes. A significance level of $P<0.05$ was used for all statistical tests.

\section{Results}

The biochemical data are shown in Table 3. In every case, none of the parameters measured on day 42 was significantly different from those measured on day 1 and there was also no significant difference between the values measured on day 1 of each dietary period; thus only the day 42 results are presented. All erythrocyte SOD, serum $\mathrm{Cu}$, serum total caeruloplasmin and plasma caeruloplasmin activity measurements fell within normal ranges; statistical evaluation of the data demonstrated that none of the parameters was affected by dietary $\mathrm{Cu}$ intake. Equilibration for 6 weeks at each $\mathrm{Cu}$ intake level was also found to have no significant effect on various risk factors related to cardiovascular disease, including ADP-stimulated platelet aggregation, plasma lipoproteins (total, HDL-, LDLcholesterol), triacylglycerols, apolipoproteins A1 and B and GPx (Table 4). Other haematological factors were also unaffected by dietary $\mathrm{Cu}$ intake including haemoglobin, mean cell haemoglobin concentration and packed cell volume (Table 5).

All data for efficiency of $\mathrm{Cu}$ absorption for the low $(0.7 \mathrm{mg} / \mathrm{d})$, medium $(1.6 \mathrm{mg} / \mathrm{d})$ and high $(6.0 \mathrm{mg} / \mathrm{d}) \mathrm{Cu}$ intake levels are presented in Table 6. Apparent absorption data for eleven of the twelve volunteers are presented due

Table 2. Unlabelled copper endogenous losses and balance data†

\begin{tabular}{|c|c|c|c|c|c|c|c|}
\hline \multirow[b]{2}{*}{ Dietary Cu intake $(\mathrm{mg} / \mathrm{d}) \ldots$} & \multirow[b]{2}{*}{$n$} & \multicolumn{2}{|c|}{$6 \cdot 0$} & \multicolumn{2}{|c|}{$1 \cdot 6$} & \multicolumn{2}{|c|}{0.7} \\
\hline & & Mean & SD & Mean & SD & Mean & SD \\
\hline Cu recovered in faeces $\ddagger$ (mg/d) & 12 & $5 \cdot 25$ & 1.05 & $1 \cdot 60^{*}$ & 0.31 & $0.83^{\star}$ & 0.32 \\
\hline Balance $(\mathrm{mg} / \mathrm{d})$ & 6 & 0.75 & 1.05 & $0.00^{*}$ & 0.31 & $-0 \cdot 13^{*}$ & 0.32 \\
\hline Slow pool§ (mg/d) & 6 & $1 \cdot 33$ & $1 \cdot 15$ & 0.58 & 0.15 & $0.35^{\star}$ & 0.25 \\
\hline Fast pooll| (mg/d) & 6 & $1 \cdot 14$ & 0.29 & $0 \cdot 23^{*}$ & 0.09 & $0 \cdot 10^{*}$ & 0.02 \\
\hline Total (slow pool+fast pool) (mg/d) & 6 & $2 \cdot 46$ & $1 \cdot 11$ & $0 \cdot 81^{*}$ & 0.16 & $0.45^{\star}$ & 0.25 \\
\hline
\end{tabular}
(Mean values and standard deviations)

* Mean value was significantly different $(P<0.05)$ from the value on the high Cu diet.

†For details of subjects and procedures, see Table 1 and p. 162.

$\ddagger$ Based on the unlabelled Cu recovered $14 \mathrm{~d}$ after label administration.

$\S \mathrm{Cu}$ absorbed from a meal and excreted at least $14 \mathrm{~d}$ after the meal.

\| Cu absorbed from the meal and excreted within $14 \mathrm{~d}$ of the meal.

Table 3. Putative indices of copper status after 6 weeks of each dietary period ${ }^{*}$

\begin{tabular}{|c|c|c|c|c|c|c|}
\hline \multirow[b]{2}{*}{ Dietary $\mathrm{Cu}$ intake $(\mathrm{mg} / \mathrm{d}) \ldots$} & \multicolumn{2}{|c|}{$6 \cdot 0$} & \multicolumn{2}{|c|}{1.6} & \multicolumn{2}{|c|}{0.7} \\
\hline & Mean & SD & Mean & SD & Mean & SD \\
\hline Erythrocyte superoxide dismutase activity (U/g haemoglobin) & 1016 & 79 & 1070 & 120 & 1009 & 113 \\
\hline Serum Cu $(\mu \mathrm{mol} / \mathrm{l})$ & $15 \cdot 5$ & $2 \cdot 2$ & 13.9 & 1.7 & 14.4 & $2 \cdot 1$ \\
\hline Serum caeruloplasmin $(\mathrm{g} / \mathrm{l})$ & 0.28 & 0.14 & 0.23 & 0.07 & 0.21 & 0.04 \\
\hline Plasma caeruloplasmin activity (U/mg) & $2 \cdot 62$ & 0.48 & $2 \cdot 29$ & 0.39 & $2 \cdot 60$ & 0.64 \\
\hline
\end{tabular}
(Mean values and standard deviations for twelve subjects)

${ }^{*}$ For details of subjects and procedures, see Table 1 and p. 162. 
Table 4. Biochemical indices denoting increased risk of cardiovascular disease measured after 6 weeks at each level of copper intake*

(Mean values and standard deviations for twelve subjects)

\begin{tabular}{|c|c|c|c|c|c|c|}
\hline \multirow[b]{2}{*}{ Dietary Cu intake $(\mathrm{mg} / \mathrm{d}) \ldots$} & \multicolumn{2}{|c|}{$6 \cdot 0$} & \multicolumn{2}{|c|}{$1 \cdot 6$} & \multicolumn{2}{|c|}{0.7} \\
\hline & Mean & SD & Mean & SD & Mean & SD \\
\hline Platelet aggregation (\%) & 80 & 10 & 80 & 7 & 82 & 5 \\
\hline \multicolumn{7}{|l|}{ Plasma lipoproteins (mmol/l) } \\
\hline Total cholesterol & $5 \cdot 0$ & 0.9 & $5 \cdot 2$ & $1 \cdot 1$ & $5 \cdot 1$ & $1 \cdot 1$ \\
\hline LDL-cholesterol & 3.3 & 0.9 & 3.4 & 1.0 & 3.5 & 1.0 \\
\hline HDL-cholesterol & $1 \cdot 1$ & 0.2 & 1.0 & 0.2 & $1 \cdot 1$ & 0.2 \\
\hline Triacylglycerols (mmol/l) & 1.24 & 0.43 & 1.51 & 0.94 & $1 \cdot 19$ & 0.53 \\
\hline Apolipoprotein A1 (g/l) & 1.14 & 0.04 & $1 \cdot 10$ & 0.04 & $1 \cdot 19$ & 0.04 \\
\hline Apolipoprotein B (g/l) & 1.08 & 0.1 & 0.96 & 0.80 & 0.93 & 0.09 \\
\hline \multicolumn{7}{|l|}{ Glutathione peroxidase } \\
\hline Erythrocyte (U/g haemoglobin) & 45 & 9 & 47 & 10 & 47 & 9 \\
\hline Plasma (U/g protein) & 9 & 1 & 9 & 2 & 9 & 2 \\
\hline Platelets (U/g protein) & 265 & 120 & 225 & 101 & 347 & 252 \\
\hline
\end{tabular}

${ }^{*}$ For details of subjects and procedures, see Table 1 and p. 162.

Table 5. Haematological and haemostatic measurements after 6 weeks at each level of copper intake* (Mean values and standard deviations)

\begin{tabular}{|c|c|c|c|c|c|c|c|}
\hline \multirow[b]{2}{*}{ Dietary Cu intake $(\mathrm{mg} / \mathrm{d}) \ldots$} & \multirow[b]{2}{*}{$n$} & \multicolumn{2}{|c|}{$6 \cdot 0$} & \multicolumn{2}{|c|}{$1 \cdot 6$} & \multicolumn{2}{|c|}{$0 \cdot 7$} \\
\hline & & Mean & SD & Mean & SD & Mean & SD \\
\hline Packed cell volume (\%) & 11 & $45 \cdot 7$ & 4.0 & 44.5 & $3 \cdot 3$ & $44 \cdot 1$ & $1 \cdot 3$ \\
\hline Haemoglobin $(\mathrm{g} / \mathrm{l})$ & 12 & 151 & 13 & $150 \dagger$ & 7 & 148 & 5 \\
\hline $\mathrm{MCHC}(\mathrm{g} / \mathrm{l})$ & 11 & 331 & 8 & 336 & 13 & 335 & 6 \\
\hline Ferritin $\ddagger(\mathrm{ng} / \mathrm{ml})$ & 12 & $29 \cdot 3$ & $14 \cdot 9,57 \cdot 8$ & $47 \cdot 3$ & $18 \cdot 7,119 \cdot 3$ & 30.6 & $12 \cdot 5,74.9$ \\
\hline
\end{tabular}

$\mathrm{MCHC}$, mean cell haemoglobin concentration.

*For details of subjects and procedures, see Table 1 and p. 162.

$\dagger$ Values for eleven subjects.

$\ddagger$ Values are geometric means $(-1 \mathrm{SD},+1 \mathrm{SD})$.

Table 6. Copper absorption and endogenous losses (from an oral dose of $3 \mathrm{mg}$ copper label) measured after 6 weeks of each dietary period*

(Mean values and standard deviations)

\begin{tabular}{|c|c|c|c|c|c|c|c|}
\hline \multirow[b]{2}{*}{ Dietary Cu intake $(\mathrm{mg} / \mathrm{d}) \ldots$} & \multirow[b]{2}{*}{$n$} & \multicolumn{2}{|c|}{$6 \cdot 0$} & \multicolumn{2}{|c|}{1.6} & \multicolumn{2}{|c|}{0.7} \\
\hline & & Mean & SD & Mean & SD & Mean & SD \\
\hline \multicolumn{8}{|l|}{ Apparent absorption } \\
\hline $\begin{array}{l}\% \\
\mathrm{mg}\end{array}$ & 11 & $\begin{array}{l}45 \\
1.34\end{array}$ & $\begin{array}{c}13 \\
0.38\end{array}$ & $\begin{array}{l}42 \\
1 \cdot 27\end{array}$ & $\begin{array}{l}15 \\
0.44\end{array}$ & $\begin{array}{l}41 \\
1.23\end{array}$ & $\begin{array}{l}12 \\
0.35\end{array}$ \\
\hline \multicolumn{8}{|l|}{ True absorption } \\
\hline $\begin{array}{l}\% \\
\mathrm{mg}\end{array}$ & 6 & $\begin{array}{l}48 \\
1.45\end{array}$ & $\begin{array}{l}11 \\
0.33\end{array}$ & $\begin{array}{l}45 \\
1.36\end{array}$ & $\begin{array}{l}14 \\
0.41\end{array}$ & $\begin{array}{l}48 \\
1.45\end{array}$ & $\begin{array}{l}13 \\
0.39\end{array}$ \\
\hline \multicolumn{8}{|l|}{ Endogenous loss of labelt } \\
\hline $\begin{array}{l}\% \\
\mathrm{mg}\end{array}$ & 6 & $\begin{array}{l}40 \\
0.58\end{array}$ & $\begin{array}{l}11 \\
0.17\end{array}$ & $\begin{array}{l}38 \\
0.48\end{array}$ & $\begin{array}{l}20 \\
0.22\end{array}$ & $\begin{array}{l}30 \\
0.40\end{array}$ & $\begin{array}{l}15 \\
0.10\end{array}$ \\
\hline
\end{tabular}

${ }^{*}$ For details of subjects and procedures, see Table 1 and p. 162.

† Absorbed label excreted within $14 \mathrm{~d}$ of dose administration.

to incomplete stool collection for one of the volunteers. Data for true absorption are reduced to six data sets because the method used to calculate true absorption failed on five other volunteers due to slow transit times of these subjects. This resulted in an inadequate number of stools being available in the later stages of the faecal collection period containing only ${ }^{65} \mathrm{Cu}$ stable isotope dose resulting from endogenous losses. The mean apparent absorption of the $3 \mathrm{mg}$ label for eleven of the volunteers on the low $\mathrm{Cu}$ intake was not significantly different from the apparent absorption of the dose at the high dietary intake level. There was no significant difference in apparent absorption between the medium and high or medium and low $\mathrm{Cu}$ intakes. 
Generally, the non-absorbed label was excreted in the faeces within $6 \mathrm{~d}$ of administration of the dose. This was validated by the simultaneous and complete recovery of the Ho dose (mean recovery was 98 (SEM 5) \%). Labelled $\mathrm{Cu}$ appearing in the faeces after this time was attributed to endogenous losses. Labelled endogenous losses were calculated using the method of Harvey et al. (2002) and were significantly lower on the low- and medium- $\mathrm{Cu}$ diets compared with the high- $\mathrm{Cu}$ diet (Table 6).

True absorption was estimated by adjusting the apparent absorption, as determined from faecal monitoring, with the endogenous loss measurements of the recovered label in these subjects (Table 6). True absorption was found to follow the same pattern as apparent absorption; absorption on the low-Cu diet was not significantly different from the high- $\mathrm{Cu}$ diet. There was no significant difference in the absorption between the medium and either the high or low $\mathrm{Cu}$ intakes.

Balance is measured as the difference between dietary intake of unlabelled $\mathrm{Cu}$ and unlabelled $\mathrm{Cu}$ recovered in the faeces. It can be seen from Table 2 that, on average, the volunteers are in negative balance on the low-Cu diet and positive balance on the medium- and high- $\mathrm{Cu}$ diets. Balance on the high- $\mathrm{Cu}$ diet was significantly greater than for both the medium- and low-Cu diets. However, the difference between the medium- and low-Cu diets was not significant. For the labelled $\mathrm{Cu}$, volunteers on the low-Cu diet retained 1.05 (SD 0.40) $\mathrm{mg}$ of the label $14 \mathrm{~d}$ after administration compared with 0.88 (SD 0.44 ) $\mathrm{mg}$ on the medium- $\mathrm{Cu}$ diet and 0.87 (SD 0.26) $\mathrm{mg}$ on the high- $\mathrm{Cu}$ diet. The difference between the low- and high- $\mathrm{Cu}$ diet values was not significant.

In the present experiment, total endogenous losses can be divided into two parts: fast and slow loss. The 'fast' loss is $\mathrm{Cu}$ that has been absorbed from a meal and then excreted within $14 \mathrm{~d}$. The 'slow' loss is absorbed $\mathrm{Cu}$ that is excreted in the faeces more than $14 \mathrm{~d}$ after the meal was consumed. The total daily endogenous loss is calculated from the quantity of absorbed $\mathrm{Cu}$ per $\mathrm{d}$ plus the difference between dietary intake and recovered faecal $\mathrm{Cu}$. This assumes that the quantity of $\mathrm{Cu}$ lost via other routes (for example, urine) is small. These data are presented in Table 2 for the unlabelled $\mathrm{Cu}$. The total endogenous loss on the high- $\mathrm{Cu}$ diet was significantly different from both the medium- $(P=0.001)$ and low-Cu diets $(P<0.001)$. A similar significant difference was observed for the rate of endogenous loss from the fast pool on the high- $\mathrm{Cu}$ diet compared with the medium$(P<0.001)$ and low-Cu diets $(P<0.001)$. The rate of endogenous loss from the slow pool was calculated as the difference between the total and the fast rates of loss (Table 2). The rate of loss was significantly greater on the high- than on the low-Cu diet $(P=0.023)$. No significant difference was observed between the highand medium- $\mathrm{Cu}$ diets.

The habitual dietary $\mathrm{Cu}$ intake of each of the volunteers was determined from both calculated and direct measurements. The mean analysed daily intake was 1.8 (SD 0.5) $\mathrm{mg}$ with a range of $0.8-2.8 \mathrm{mg} / \mathrm{d}$ and was significantly higher $(P=0.021)$ than the calculated value of 1.4 (SD 0.5$) \mathrm{mg}$ with a range of $0.7-2.5 \mathrm{mg} / \mathrm{d}$.

\section{Discussion}

From the results presented it appears that $\mathrm{Cu}$ homeostasis is maintained through control of only endogenous excretion and not absorption. Although the present study does not include data on urinary output, it has been reported that this form of excretion is minimal (Ishihara \& Matsushiro, 1986) and is not dependent on dietary $\mathrm{Cu}$ intake. Turnlund et al. $(1989,1998)$ have performed two dietary intervention studies with male volunteers, feeding $\mathrm{Cu}$ levels similar to those used in the present study. Stable-isotope methodology was used to determine apparent absorptions of 56 and $54 \%$ following equilibration at $\mathrm{Cu}$ intake levels of 0.785 and $0.66 \mathrm{mg} / \mathrm{d}$ respectively, higher than the mean apparent absorption of $41 \%$ found on the low-Cu diet $(0.7 \mathrm{mg} / \mathrm{d})$ in the present study. Daily intakes of 7.53 and $1.68 \mathrm{mg} \mathrm{Cu}$ were found to result in apparent absorptions of 12 and $36 \%$ respectively (Turnlund et al. 1989). These values are, however, lower than the values found in the present study, which may be the result of differences in experimental protocol. First, the present study measured absorption from a single test meal, which has been reported to over-estimate absorption compared with measurement over several meals as used by Turnlund et al. (1989). Second, in the present study, in order to be able to calculate endogenous losses, $3 \mathrm{mg}$ labelled $\mathrm{Cu}$ was given in a single test meal on each of the high-, medium- and low-Cu diets, whereas in the study by Turnlund et al. (1998) $\mathrm{Cu}$ in the study meals was replaced with the same quantity of $\mathrm{Cu}$ label.

The study by Turnlund et al. (1998) estimated endogenous losses by measuring the faecal appearance of intravenous doses of highly enriched ${ }^{65} \mathrm{Cu}$ stable isotope. In agreement with our data, endogenous losses were found to be reduced with low dietary $\mathrm{Cu}$ intake when compared with higher intake levels. A $\mathrm{Cu}$ metabolism model based on the disappearance of both infused and oral ${ }^{65} \mathrm{Cu}$ dose has suggested that tissue uptake of oral and intravenous $\mathrm{Cu}$ is different, with flow between the plasma and liver compartment from the intravenous dose only being $80 \%$ of the oral dose (Scott \& Turnlund, 1994). The intravenous technique gives a general indication of the relative changes in endogenous losses resulting from different dietary $\mathrm{Cu}$ intakes, whereas the technique used in the present study has the advantage of reflecting the metabolism of the absorbed oral dose in the same volunteer during the same time period as the absorption efficiency is assessed.

Within $14 \mathrm{~d}, 38$ (SD 20) \% of the absorbed oral dose had been excreted when the volunteers were on the medium-Cu diet. From the retention data of the unlabelled $\mathrm{Cu}$ it is known that the volunteers were in balance (Table 2). This indicates that the other $76 \%$ of the absorbed label will be excreted at a future indeterminate time from a slowly exchangeable pool in the body. When the volunteers were on the high-Cu diet, 40 (SD 11) \% of the absorbed dose was excreted $14 \mathrm{~d}$ after the dose was given. The volunteers were not, however, in balance $(0.75 \mathrm{mg} / \mathrm{d}$ was retained $)$. It is not clear from our study or others (Turnlund et al. 1989; 1998) how long, if at all, it would take to restore $\mathrm{Cu}$ balance on such a high- $\mathrm{Cu}$ 
diet. Losses from the rapidly exchanging (fast) pool alter significantly between the diets (Table 2). There is a fivefold increase between the medium- and high- $\mathrm{Cu}$ diets in this fast pool but only a two-fold increase in the slow pool loss between the same two diets. This fast pool can clearly respond to changes in dietary conditions much more readily than the slow pool and indicates that the physical locations of the fast pool are a series of rapidly turning over spaces that certainly include the liver in some capacity.

Linder et al. (1986) and Owen (1971) have shown in rats that the loss of $\mathrm{Cu}$ from the body can be represented by a biphasic equation. Our model of endogenous loss assumed that the labelled $\mathrm{Cu}$ was lost according to a linear equation (of the form $y=\mathrm{m} x+\mathrm{c}$ ) since this is all that can be justified from the data. Fig. 2 and Table 7 show an attempt to estimate the endogenous loss in one volunteer on the high$\mathrm{Cu}$ diet by applying three different mathematical models to the data. In all three models, estimates of endogenous loss are made beyond the time that measurements were taken (14 d). After $30 \mathrm{~d}$ of the mono- and bi-exponential simulations and $19 \mathrm{~d}$ of the linear one, there is still at least

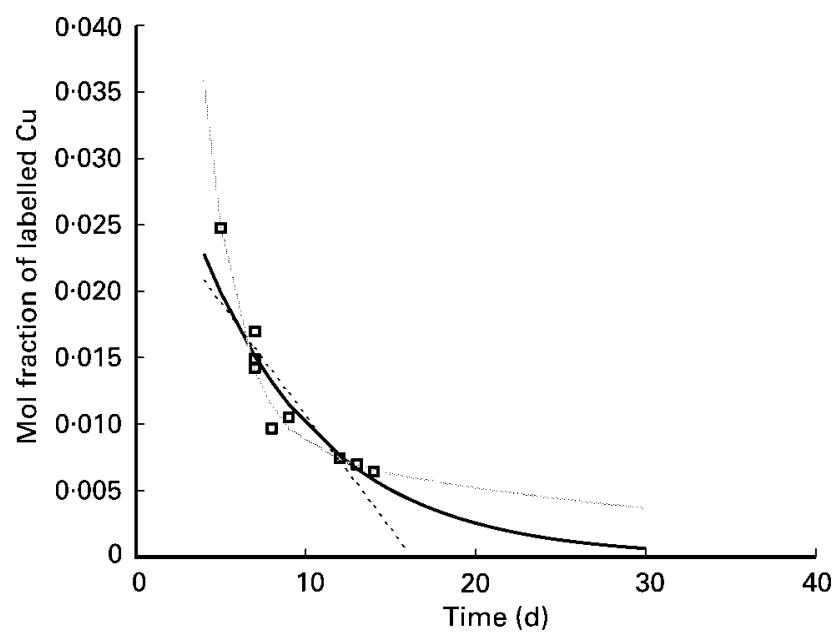

Fig. 2. Effect of different endogenous excretion models on fraction of labelled copper absorbed and then expelled in faeces. Data are for a single volunteer on the high-copper diet. (-), Mono-exponential model; $(\sim \sim)$, bi-exponential model; (---), linear model; $(\square)$, measured values.

Table 7. Comparison of three models fitted to re-excreted oral dose data for a single volunteer on the high-copper diet

\begin{tabular}{|c|c|c|c|}
\hline & $\begin{array}{c}\mathrm{Bi}- \\
\text { exponential }\end{array}$ & $\begin{array}{c}\text { Mono- } \\
\text { exponential }\end{array}$ & Linear \\
\hline Absorption (\%) & 78 & 71 & 69 \\
\hline Absorbed $(\mu \mathrm{g})$ & 2340 & 2114 & 2060 \\
\hline $\begin{array}{l}\text { 'Fast' pool endogenous } \\
\text { excretion }(\mu \mathrm{g})\end{array}$ & $1230^{*}$ & $844^{*}$ & 736† \\
\hline $\begin{array}{l}\text { Amount excreted } \\
\text { (fast pool) }(\%)\end{array}$ & 53 & 40 & 36 \\
\hline Retained $(\mu \mathrm{g})$ & $1110 \neq$ & $1270 \neq$ & $1324 \S$ \\
\hline
\end{tabular}

* Simulated for $30 \mathrm{~d}$ after oral dose.

† Simulated for $19 \mathrm{~d}$ after oral dose at which point the excretion is zero.

$\ddagger$ Retained in body $30 \mathrm{~d}$ after oral dose.

$\S$ Retained in body $19 \mathrm{~d}$ after oral dose.
$1 \mathrm{mg}$ absorbed $\mathrm{Cu}$ that has not been excreted. The intervention periods were 6 weeks and the volunteers on the medium- and low-Cu diets were in balance at the end of them. This suggests that a complex excretory system exists for $\mathrm{Cu}$ and that our attempts at simple models are not adequate to describe it. The division of endogenous losses into two pools (slow and fast) is an over simplification but is all that can be attempted with a study of this type. Single meal stable-isotope studies with physiological doses cannot, at present, measure the return of labelled $\mathrm{Cu}$ from slow turnover pools because their half-life is too long. The physical nature of the slow pool (or pools) is a matter for conjecture but the most probable candidates are muscle and bone. Whatever the nature of the pool, it appears to be under homeostatic control, as evidenced by a doubling of $\mathrm{Cu}$ flowing from it between the low- to medium- and medium- to high-Cu diets, although it had not changed sufficiently over the 6 weeks of the high-Cu diet to achieve $\mathrm{Cu}$ balance.

The results of the present study indicate that homeostasis is more strongly controlled by endogenous excretion. Absorption did not change in response to variations in $\mathrm{Cu}$ intake. A four-fold dietary increase in $\mathrm{Cu}$ (medium- to high- $\mathrm{Cu}$ diet) would necessitate a four-fold reduction in absorption (60 to $15 \%)$ if this were the body's only homeostatic mechanism. Similarly, the change in absorption between the medium- and the low-Cu diet was 45 to $48 \%$, whereas the reduction in dietary $\mathrm{Cu}$ between the two periods was approximately a factor of two.

An attempt has been made in the present paper to use the data from the re-excreted oral dose to calculate endogenous losses. This allows quantification of the so-called fast pool of endogenous loss. Although a linear model has been used to calculate these losses, other researchers, using radioisotope data, have shown that a biphasic curve represents the endogenous loss in the best way. Using physiological doses of stable isotope, measurements of enrichment in faeces are possible up to about $14 \mathrm{~d}$ post-dose. After this length of time, the precision is not sufficient to use the data. This limits the complexity of any models derived from stableisotope data to only the simplest kind, i.e. linear regression models. Although the modelling is simple, it still generates useful information and allows the calculation of two $\mathrm{Cu}$ loss pools (fast and slow) through direct and indirect means. Overall, the data suggest that adaptive responses to a high dietary intake take longer to achieve than at lower intakes. The fact that none of the biochemical measurements changed as a result of altered $\mathrm{Cu}$ intake lends support to our hypothesis that adult men faced with quite large variations in $\mathrm{Cu}$ intake are able to maintain $\mathrm{Cu}$ homeostasis predominantly by up and down regulation of $\mathrm{Cu}$ secretions into the gastrointestinal tract.

\section{Acknowledgements}

The authors would like to thank Yvonne Clements and Lynne Sanchez for their technical assistance with the design and preparation of the diets, and the University of Ulster Coleraine FOODCUE team. This work was supported by the Food Standards Agency (formerly 
MAFF; projects ANO509 and ANO515), the European Commission (grant CT 95-0813; FOODCUE) and the Biological and Biotechnological Sciences Research Council.

\section{References}

August D, Janghorbani M \& Young VR (1989) Determination of zinc and copper absorption at three different $\mathrm{Zn}-\mathrm{Cu}$ ratios by using stable isotope methods in young and elderly subjects. Am J Clin Nutr 50, 1457-1463.

Baxter MJ, Crews HM, Robb P \& Strutt PR (1997) Quality control in the multi-element analysis of foods using ICP-MS. In Plasma Source Mass Spectrometry: Developments and Applications, Special Publication no. 202, pp. 95-109 [G Holland and SC Tanner, editors]. Cambridge: Royal Society of Chemistry.

Cordano A, Baertl JM \& Graham GG (1964) Copper deficiency in infancy. Pediatrics 34, 324-326.

Dorner K, Dziadzka S, Hohn A, Sievers E, Oldigs HD, Schulz-Lell G \& Schaub J (1989) Longitudinal manganese and copper balances in young infants and preterm infants fed on breast milk and adapted cow's milk formulas. $\mathrm{Br} J \mathrm{Nutr}$ 61, 559-572.

Drabkins DL \& Austin JH (1932) Spectrophotometric constants for common hemoglobin derivatives in human, dog and rabbit blood. J Biol Chem 98, 719-733.

Friedewald WT, Levy RI \& Frederickson DS (1972) Estimation of the concentration of low-density lipoprotein cholesterol in plasma, without use of the preparative ultracentrifuge. Clin Chem 18, 499-502.

Goyens O, Brasseur D \& Cadranel S (1985) Copper deficiency in infants with active celiac disease. J Pediatr Gastroenterol Nutr 4, 677-680.

Harvey LJ, Majsak-Newman G, Dainty JR, Wharf SG, Reid MD, Beattie JH \& Fairweather-Tait SJ (2002) Holmium as a fecal marker for copper absorption studies in adults. Clin Sci 102, 233-240.

Henry RJ, Chiamori N, Jacobs SL \& Segalove M (1960) Determination of ceruloplasmin oxidase in serum. Proc Soc Exp Biol Med 104, 620-624.

Ishihara N \& Matsushiro T (1986) Biliary and urinary excretion of metals in humans. Arch Environ Health 41, 324-330.
Jones DG \& Suttle NF (1981) Some effects of copper deficiency on leucocyte function in sheep and cattle. Res Vet Sci 31, $151-156$.

Linder MC (1991) The Biochemistry of Copper. New York, NY: Plenum Press.

Linder MC \& Roboz M and the Los Alamos Medical Radioisotope Research Group (1986) Turnover and excretion of copper in rats as measured with ${ }^{67} \mathrm{Cu}$. Am J Physiol 251, E551-E555.

Owen CA (1971) Metabolism of copper 67 by the copperdeficient rat. Am J Physiol 221, 1722-1727.

Paglia DE \& Valentine WN (1967) Studies on the quantitative and qualitative characterization of erythrocyte glutathione peroxidase. J Lab Clin Med 70, 158-169.

Reiser S, Smith JC Jr, Mertz W, Holbrook JT, Schofield DJ \& Powell AS (1985) Indices of copper status in humans consuming a typical American diet containing either fructose or starch. Am J Clin Nutr 42, 242-251.

Royal Society of Chemistry (1991) McCance \& Widdowson's The Composition of Foods, 5th ed. [B Holland, AA Welch, ID Unwin, DH Buss, AA Paul and DAT Southgate, editors]. London: Royal Society of Chemistry and Ministry of Agriculture, Fisheries and Food.

Scott KC \& Turnlund JR (1994) Compartmental model of copper metabolism in adult men. $J$ Nutr Biochem 5, 342-350.

Turnlund JR, Keyes WR, Anderson HL \& Acord LL (1989) Copper absorption and retention in young men at three levels of dietary copper using the stable isotope ${ }^{65} \mathrm{Cu}$. Am J Clin Nutr 49, 870-878.

Turnlund JR, Keyes WR, Hudson CA, Betschart AA, Kretsch MJ \& Sauberlich HE (1991) A stable isotope study of zinc, copper and iron absorption and retention by young women fed vitamin B-6 deficient diets. Am J Clin Nutr 54, 1059-1064.

Turnlund JR, Keyes WR, Peiffer GL \& Scott KC (1998) Copper absorption, excretion and retention by young men consuming low dietary copper determined by using the stable isotope ${ }^{65} \mathrm{Cu}$. Am J Clin Nutr 67, 1219-1225.

Turnlund JR, Wada L, King JC, Keyes WR \& Acord LL (1988) Copper absorption in young men fed adequate and low zinc diets. Biol Trace Elem Res 17, 31-41.

Williams WJ, Beutler E, Erslev AJ \& Rundles RW (1977) Hematology. New York, NY: McGraw-Hill. 